\title{
Parental Perspectives on Children's School Readiness: An Ethnographic Study
}

\author{
Kim Jose ${ }^{1}\left[\right.$. Susan Banks ${ }^{2} \cdot$ Emily Hansen $^{2} \cdot$ Rachael Jones $^{3} \cdot$ Stephen R. Zubrick ${ }^{4}$ Joel Stafford ${ }^{4}$. \\ Catherine L. Taylor ${ }^{1,4}$
}

Accepted: 3 November 2020 / Published online: 18 November 2020

(c) The Author(s) 2020

\begin{abstract}
School readiness is a construct used by educators and policy makers to describe a range of abilities that are beneficial for children transitioning to school. The association of socioeconomic disadvantage with developmental vulnerability when children start school is well established. Parents play a crucial role in supporting children's transition to school and are acknowledged as their child's first and foremost teacher. The aim of this study was to explore how parents experience and support their children's transition to school. This study presents findings from an ethnographic study with 39 parents living in two Australian communities characterised by high area-level socioeconomic disadvantage. The study reports on how parents experience and support their child for transition to school, specifically through their understanding of the concept of 'readiness'. The role of early childhood services in supporting parents is also explored. Parents conceptualised school readiness as the child's capacity to function effectively and independently in the hitherto unfamiliar physical and social world of school. Parents considered early childhood services supportive of their children's transition to school, particularly the development of social skills.
\end{abstract}

Keywords Transition to school $\cdot$ Ethnography $\cdot$ Vulnerable families $\cdot$ Early childhood services

\section{Introduction}

Starting school is a significant milestone in the life of a child and their parents or carers. The success of children's transition to school is influenced by their individual capabilities, those of their parents and the relationships,

Electronic supplementary material The online version of this article (https://doi.org/10.1007/s10643-020-01130-9) contains supplementary material, which is available to authorized users.

Kim Jose

kim.jose@utas.edu.au

Susan Banks

Susan.banks@utas.edu.au

Emily Hansen

emily.hansen@utas.edu.au

Rachael Jones

Rachael.jones@utas.edu.au

Stephen R. Zubrick

Stephen.Zubrick@telethonkids.org.au

Joel Stafford

joel.stafford@education.tas.gov.au resources, and opportunities they experience at home and in early childhood settings before they start full-time school (Bronfenbrenner and Morris 2006, United Nations Children's Fund (UNICEF) 2012, Tayler et al. 2015, Organization for Economic Co-operation and Development 2016). "School readiness" is the term commonly used to describe individual capabilities of children when they start school. It is a multidimensional concept that includes a child's physical health and wellbeing, social

Catherine L. Taylor

Cate.Taylor@telethonkids.org.au

1 Menzies Institute for Medical Research, University of Tasmania, Hobart, TAS 7000, Australia

2 School of Social Sciences, University of Tasmania, Private Bag 22, Hobart, TAS 7001, Australia

3 School of Social Sciences, University of Tasmania, Locked Bag 1340, Launceston, TAS 7250, Australia

4 Telethon Kids Institute and Centre for Child Health Research, The University of Western Australia, 15 Hospital Avenue, Nedlands, WA 6009, Australia 
and emotional competence, language and cognitive development, communication skills and general knowledge (Guhn et al. 2016; Miller and Kehl 2019), as well as attitudes towards learning in the classroom (e.g., interest and engagement) and classroom skills and behaviours (e.g., following instructions, cooperating with a group) (Domitrovich et al. 2012). Children, their families, communities, early childhood services, and schools are all involved in preparing children for the transition to school.

Inequalities in school readiness at the start of full-time school have far-reaching consequences for success at school, with achievement gaps widening over time (Taylor et al. 2019). Globally, the first 5 years of a child's life is recognised as a critical period for assisting all children to achieve their developmental potential and overcoming developmental disadvantage through early interventions (Britto et al. 2017). In Australia, government policies (Council of Australian Governments 2009) aimed at improving children's developmental circumstances and outcomes are informed by population-wide monitoring of child development in the first year of full-time school (i.e., Australian Early Development Census: AEDC) (Brinkman et al. 2014) and academic achievement in school Years 3, 5, 7 and 9 through the National Assessment Program - Literacy and Numeracy: NAPLAN (Australian Curriculum Assessment and Reporting Authority 2016). The AEDC is a populationbased measure of Australian children's development in their first year of full-time schooling across five domains: (1) Physical health and wellbeing, (2) Social competence, (3) Emotional maturity, (4) Language and cognitive skills (school-based), and (5) Communication skills and general knowledge. The AEDC is conducted nationally every 3 years with the first national data collection occurring in 2009 and the most recent in 2018. The Early Development Instrument is completed by the classroom teacher and used to calculate a domain score in each of the five domains. Using the score and national AEDC cut-offs children are assessed as "on track", "at risk" or "vulnerable" in each of the five domains. The AEDC results inform early years policy and service provision, at state and federal levels. The AEDC also aims to drive improvements in developmental outcomes for children through parents, schools and communities working together; providing parents with information about how to support their child's development across the five AEDC domains (Department of Education and Training 2020).

In 2016, the Tassie Kids project was established in partnership with the Tasmanian Departments of Health, Education, and Premier and Cabinet to investigate the uptake and reach of universal early childhood health and education services excluding child care services (i.e., Launching into Learning (LiL), Child and Family Centres (CFCs), Child Health and Parenting Service (CHaPS), Kindergarten (Kinder); see Table 1), particularly with more vulnerable families. This ethnographic study explored parents' perspectives on school readiness and the role of parents and early childhood services (ECS) in preparing children for school.

\section{Methods}

\section{Study Design}

An ethnographic study design was selected as it provides indepth insights into people's views and actions with respect to their situation or location, through the collection of detailed observations and interviews (Reeves et al. 2008). Ethical approval was received from the Human Research Ethics Committee (Tasmania) (H0016195).

\section{Sites}

This ethnographic study was conducted in two primary sites in Tasmania with data supplemented from two additional sites. Primary site selection was informed by data on births, area-level socioeconomic disadvantage, service use, Australian Early Development Census (AEDC) results, the presence or absence of a CFC, and input from government partners from the early childhood health and education sectors (Department of Education and Training 2015; Australian Bureau of Statistics 2016; Taylor et al. 2017). The primary sites included one rural community with a CFC (pseudonym, Distant Hills) and one suburban area without a CFC (pseudonym, River Town).

Distant Hills, a rural region with a population of just over 10,000 people (Australian Bureau of Statistics 2016), has one main township (population $>5,000$ ) surrounded by several smaller towns. A CFC is situated near the centre of the main town. There were five government primary schools offering LiL located throughout Distant Hills, two in the main township and three in surrounding towns. River Town, a small (population 1000) outer suburb of a major urban area, has an existing community centre offering a range of services and one primary school offering LiL. Another primary school is situated in an adjoining suburb.

In Australia, the Index of Relative Socioeconomic Disadvantage (IRSD) ranks areas from 1 to 10 in terms of their relative socio-economic disadvantage using information on the economic and social conditions of people and households (Australian Bureau of Statistics 2016): 1 = high disadvantage and $10=$ low disadvantage. Distant Hills and River Town have IRSD ratings of 1, placing them amongst the most disadvantaged communities in Australia (Australian Bureau of Statistics 2016). The additional sites were two CFCs located in different regions of the state, one a town of over 18,000 people and the other a small town of just over 2000 people, which serviced the surrounding 
Table 1 Summary of universal early childhood services

\begin{tabular}{|c|c|c|c|}
\hline Service & Anacronym & Government Department Responsible & Service characteristics \\
\hline Child Health and Parenting Service & $\mathrm{CHaPS}$ & Department of Health and Human Services & $\begin{array}{l}\text { Eligibility: Children aged } 0-5 \text { years } \\
\text { Community based: various settings } \\
\text { Delivered by Child Health Nurses } \\
\text { Screening health and developmental checks } \\
\text { for children: } \\
2,4 \text { and } 8 \text { weeks } \\
6 \text { and } 12 \text { months } \\
2 \text { and } 4 \text { years } \\
\text { Appointment based system } \\
\text { One open 'drop in' session per week } \\
\text { Additional targeted services available }\end{array}$ \\
\hline Launching into Learning & LiL & Department of Education & $\begin{array}{l}\text { Eligibility: Children from } 0 \text { to } 4 \text { years } \\
\text { School based, no cost } \\
\text { Delivered by early childhood teachers } \\
\text { Support child development, parent/child } \\
\text { relationships and facilitate the transition to } \\
\text { school } \\
\text { Play-based activities, excursions } \\
\text { Parents/carers present with children } \\
\text { Structured 2-h sessions } \\
\text { Available during school terms } \\
\text { Number of sessions determined by each } \\
\text { school }\end{array}$ \\
\hline Child and Family Centres & Centre or CFC & Department of Education & $\begin{array}{l}\text { Eligibility: Children from } 0 \text { to } 5 \text { years } \\
\text { Twelve sites in Tasmania } \\
\text { All CFCs staffed by Centre Leader, Com- } \\
\text { munity Inclusion Worker and an early } \\
\text { childhood teacher. Other staff vary across } \\
\text { CFCs in response to community need } \\
\text { Health, education and community services } \\
\text { offered at the Centre } \\
\text { Operate } 5 \text { days per week } \\
\text { Open year round, no charge } \\
\text { Parents and children can 'drop in' at any time }\end{array}$ \\
\hline Kindergarten & Kinder & Department of Education & $\begin{array}{l}\text { Kindergarten is a school-based program } \\
\text { that provides } 15 \mathrm{~h} \text { a week of play-based } \\
\text { learning for four-year-old children in a } \\
\text { classroom setting. The sessions are planned } \\
\text { and delivered by early childhood teach- } \\
\text { ers (Early Years Learning Framework for } \\
\text { Australia, 2007) }\end{array}$ \\
\hline
\end{tabular}

rural area. These towns were also ranked amongst the lowest two deciles of social disadvantage using the IRSD (Australian Bureau of Statistics 2016).

\section{Data Collection}

Data were collected from extensive fieldwork and observations of service provider activities and in-person interviews with service provider staff and parents. These were conducted by experienced qualitative researchers (KJ and SB) and PhD candidate (RJ) during April 2017 and December 2019. All researchers were female and had previous experience conducting qualitative studies. None were connected with the study sites where this study occurred. All participants consented to interviews and participant observation.

\section{Participant Observation}

During the data collection period (April 2017-December 2018), KJ was embedded within the CFC at Distant Hills 
and RJ was embedded in River Town. After spending 1 week full-time at the CFC KJ attended the CFC on average once per week during the data collection period (April 2017-December 2018) attending group activities and programs, attending team meetings and community activities. $\mathrm{KJ}$ also spent 1 week at each of the two additional CFCs. In addition to time spent at the CFCs, $\mathrm{KJ}$ attended all the LiL programs offered by the five primary schools in Distant Hills. Four of these programs were visited twice and one of them once.

$\mathrm{RJ}$ was embedded within River Town and also spent time in sites in surrounding suburbs that provided early childhood services and supports to families who lived in River Town. These included the local community centre, CHaPS clinic, and two local primary schools. RJ also visited more than $35 \mathrm{LiL}$ sessions delivered from the two primary schools in River Town, speaking informally with teachers and families who used the service. In addition, RJ attended local early childhood network meetings for services providing programs to families in River Town. These included government and non-government service providers. SB joined the research team towards the end of the fieldwork period and spent four days in the field, two days with $\mathrm{KJ}$ and two days with RJ.

$\mathrm{KJ}, \mathrm{SB}$ and RJ spent more than 100 days attending a range of early childhood services in Tasmania. This included LiL sessions, Kindergarten, Child and Family Centres and CHaPS clinics (see Table 1). During this time, the researchers participated in a range of activities and programs for parents and children, attended team meetings and spoke informally with service providers and families. The identity of the researcher and their purpose was made known to everyone present and did not impact on normal service delivery.

Prior to commencing fieldwork, planning and training sessions were held by senior ethnographic researcher EH. These sessions highlighted areas of interest for observation as well as the development and use of fieldnotes. Observations focused on the environment, collaboration between service providers, and interactions with and between families. Field notes were developed by each researcher after all sessions and included observations, informal conversations and reflections on the experiences of the researchers (Lofland et al. 2006). Researchers did not attend any private consultations between service providers and families. Early fieldnotes were shared and discussed by $\mathrm{EH}, \mathrm{KJ}$ and $\mathrm{RJ}$. Fieldnote practices reflected the different models of service delivery between the key sites and the backgrounds and experience of researchers in the field (Clerke and Hopwood 2014). For example, within CFCs it was possible to observe direct interactions between service providers from different sectors while in LiL service interaction commonly occurred via phone and was reported and discussed between the researcher and teacher rather than observed. A fieldwork activity log was kept by $\mathrm{KJ}$ and $\mathrm{RJ}$ to track their engagement in the field. In addition, a data recording protocol was developed by $\mathrm{KJ}$ prior to commencing fieldwork and $\mathrm{KJ}$ was responsible for data management throughout the fieldwork period. The extensive period of observation facilitated the development of trust with participants and allowed for a greater understanding of how ECSs operate and engage with families and each other. It also enabled researchers to focus their observations on key elements as they emerged. The extensive period of observation facilitated the development of trust with participants and allowed for a greater understanding of how service providers engage with families.

\section{Interviews}

\section{Parents}

Purposive sampling was used to ensure that a variety of perspectives on the topic under study was represented (Hansen 2006). In this study we were interested in the perspectives and experiences of a wide range of parents or carers including first-time parents, parents or carers with multiple children, fathers, parents or carers whose children were about to transition to school, and parents or carers of varying ages and with variable patterns of service use. Researchers participated informally with parents and carers and children in programs offered on-site before approaching parents or carers during attendance at an ECS activity. Recruitment was also aided by LiL and kindergarten teachers and CFC staff who discussed the study with families, assisted with identifying families for inclusion or approached families directly about being involved in the study. Participants were given a choice of interview location with most interviews occurring at the site of the early childhood activity. Follow-up interviews with parents were coordinated by the researchers; these interviews were conducted at the site of the early childhood activity or in the participant's home. Extensive fieldwork facilitated the recruitment of 39 parents into this study. No carers were recruited. One parent was recruited into the study but did not attend the scheduled interview. One couple was interviewed together while the remaining participants were interviewed alone. Parents received a voucher to the value of $\$ 50$ for each interview in recognition of their time. The vouchers were purchased using research funds awarded to this project. All staff who assisted with recruitment were advised that interview participants would receive a voucher. Information about the voucher was included in the written 'Information Sheet for Families' provided to all participants with the 'Family Consent Form'.

Twenty-three parents were interviewed twice with second interviews occurring between 20 and 41 weeks after the first interview. Of the 14 parents who were interviewed once, 2 were not followed up as their circumstances had changed 
and they were no longer available for interview, 2 did not attend their scheduled follow-up interview, 8 were recruited towards the end of the study to capture the perspectives of parents who were less engaged in services and insufficient time had elapsed for a follow-up interview, and in one case one parent attended the first interview and the other parent attended the scheduled follow-up interview. Parent interviews averaged $33 \mathrm{~min}$.

Initial interviews with families focused on parenting, use and experience of ECS and avenues for accessing parenting support when needed (Supplement 1). Parents were also asked about the concept of 'school readiness': had they heard of the term and what they thought it meant their child/ children should be able to do. A question about the parent's opinion about the state government's proposal to lower the school starting age was included in Interview Schedule 1 and this question was asked in 2 interviews. The question was excluded from Interview Schedule 1 when the proposal was abandoned. In follow-up interviews individually tailored questions developed from participant responses in the first interview were included. The concept of school readiness was followed up in depth with parents who were again asked what they thought 'school readiness' meant, and then prompted with descriptors from the five AEDC domains (Department of Education and Training 2015). Parents were then asked about their role and the role of services in supporting children to gain these skills prior to school (Supplement 1).

\section{Data Analysis}

Interview audio-recordings were fully transcribed and any relevant interview field notes were attached to the de-identified transcripts before importing into the qualitative data analysis software program NVivo 11 (QSR International 2012). A preliminary transcript analysis was conducted soon after the interview so the researchers could take insights from that interview into any subsequent interviews. Initial codes were developed from the data (a type of open coding) and included many in-vivo codes. Following a process of compare and contrast, the codes were then sorted, refined, and regrouped into higher order conceptual categories. Data pertaining to discussions on school readiness from all interviews were then collated and preliminary analysis by $\mathrm{KJ}$ and SB involved coding to the five domains contained in the AEDC. Further analysis using an iterative process and the constant comparison technique (Grbich 1998) to determine whether parents' discussion of developmental competencies reflected the AEDC domains. Additional concepts such as the role of parents and services in preparing children for school were coded separately. KJ and SB met regularly during analysis to refine coding processes and reach agreement on codes. Coding decisions, key concepts, ideas, and reflections were identified and recorded in the project log and memos (Cresswell 2007). For the purpose of investigator triangulation and to encourage reflexivity $\mathrm{KJ}$ met the other members of the ethnographic research team to review project memos, compare coding and refine the analysis (Bazeley and Jackson 2013). Any disagreements were resolved via discussion.

\section{Results}

Thirty-nine parents from communities of relatively high disadvantage participated in this study. All parents had at least one preschool age child (i.e., a child who had not started full-time school) and were attending pre-school programs such as LiL, kindergarten or CFCs with varying frequency. Five parents (13\%) reported undertaking any form of further education after completing senior secondary schooling and just over half reported their highest level of education was Year 10 or less (see Table 2). Results are presented according to the five themes of school readiness parents discussed: physical, behavioural, socio-emotional, literacy and numeracy, and language and communication. Three nonchild based themes are also presented: how parents see their own role in readiness, parents being prepared for school and services assisting parents and children prepare for school.

Parental discussions of school readiness revealed four specific developmental competencies that were considered critical aspects of school readiness. These were toileting (physical theme), ability to interact positively with other children (socio-emotional theme), separation from parents (socio-emotional theme), and listening (behavioural theme). The four key competencies are discussed in more detail under the relevant themes. Significantly, parents also recognised that children differed and developed at their own pace. In the results, quotes attributed to parents are identified by $\mathrm{P}$, followed by a number while quotes referring to fieldnotes will be identified as fieldnote.

\section{Physical Readiness}

For parents, independence was important and was chiefly signalled by a child's ability to manage hygiene (use the toilet and wash their hands); they also talked about children's fine and gross motor skills. Parents felt their child needed to be independently using the toilet. "You can't go to school [son], if you don't go to the toilet. And that was a really big issue" (P1). Even when children were "in night-time nappies" (P6), being able to manage their own hygiene at school was a sign of readiness.

Some parents identified the need for fine motor skills, like "holding a pen or crayon, you can encourage but it comes along later" (P3), as linked with readiness. One parent's 
Table 2 Participant characteristics

\begin{tabular}{|c|c|}
\hline Parents, $\mathrm{N}$ & 39 \\
\hline \multicolumn{2}{|l|}{ Gender $($ males $=8$, females $=31)$} \\
\hline Female $(\%)$ & 80 \\
\hline Age (average, range) years & $32.9(18-56)$ \\
\hline \multicolumn{2}{|l|}{ Parent age first child (years) } \\
\hline First child $<20$ & 12 \\
\hline First child $21-35$ & 23 \\
\hline First child $>35$ & 4 \\
\hline \multicolumn{2}{|c|}{ Number of children at first interview } \\
\hline One child & 7 \\
\hline Two/three children & 25 \\
\hline More than three children & 16 \\
\hline Average number children & 2.6 \\
\hline \multicolumn{2}{|c|}{ Number of services used (self-report) } \\
\hline Multiple (including CFC) & 24 \\
\hline CHaPS only & 2 \\
\hline LiL only & 7 \\
\hline Lil and CHaPS & 3 \\
\hline Other only & 1 \\
\hline \multicolumn{2}{|l|}{ Family structure first interview } \\
\hline Single parents & 10 \\
\hline Partner & 29 \\
\hline \multicolumn{2}{|l|}{ Education } \\
\hline Year 10 or less & 20 \\
\hline Year 11/12 (includes 1 year 13) & 13 \\
\hline Certificate & 3 \\
\hline Bachelor & 2 \\
\hline Missing & 1 \\
\hline
\end{tabular}

daughter "has had an awesome pencil grip from about 18 months old.[Son] started kinder and he still didn't know if he was left or right handed.[...] He needs a bit of extra work on his fine motor" (P19). Again, the idea that a child developed at their own pace was acknowledged.

Parents spoke of the need for children to be able to run, skip, climb and use play equipment in order to be ready for school. A second aspect of this skill set was the capacity of the child to exercise control over their body.

[Son] had an absolute ball. He loved it, he loved it. He spent time outside with other kids riding bikes, playing in the sand, swings and so on plus we also did activities inside. Drawing and colouring and painting and pasting, reading books and that sort of thing. (P14)

Pre-school services and opportunities like those provided by the CFC or LiL were recognised by parents as being part of building these skills. "It [pre-kinder] was a very important service to get him ready for kinder" (P14). These programs provided opportunities for developing greater physical skills.
Physical readiness was also understood in terms of how children use their bodies in the school setting. This readiness was evident in RJ's observation of a teacher aide referring to crossed legs as "kinder legs" and requiring a child to sit with his legs crossed during mat time (River Town fieldnotes), something they found difficult.

\section{Behavioural Readiness}

Behavioural readiness was conceptualised as the capacity to listen to teachers and follow instructions: "if they're going to listen [...] well they're going to learn aren't they?" (P10). "Listening to instructions" is part of the AEDC measures and was provided to parents as one of our prompt statements; they agreed that it was important:

No, I think to learn [...] to understand orders or whatnot, it would help when it comes to learning from a teacher. Like a teacher said, "Can you go and grab this" or "I want you to draw today." I think it might help. (P16)

Parents felt they had to prepare their child for having "to do some new things" and that "it's going to be school and that she's going to have to listen to the teacher" (P18). Children being ready to listen and follow instructions was also identified as making life easier for teachers. While listening is clearly linked to language and communication, parents' discussions reflected a behavioural aspect to this concept.

\section{Social-Emotional Readiness}

Parents in the study recognised that their children needed to be able to separate from them; this was a significant theme and is congruent with their recognition of the importance of being able to use the toilet. Both signal the child's developing independence. Parents wanted their children to be "confident enough to be away from me for a day or half a day" (P8). Being ready for school meant coping with not having "that little safety net of Mum or Dad around" (P30), and knowing "that they can be by themselves and [...] that they can socialise sort of with some other children" (P25).

Some parents found the idea of separation distressing. They were nervous about sending their child to school for the first time- "you just didn't know how he was going to go and whether he wanted to come home" (P17). Separation could be a source of anxiety, with one mother expressing concern about how her child was going to cope in kindergarten. This parent considered keeping their child at home another year because they were "very shy and did not like being away from Mum" (fieldnotes).

Parents reported that social-emotional readiness matters: they felt that children's ability to get on with teachers and with other children was part of being able to manage at 
school. They considered it important for children to develop the necessary social skills before they started full-time school. In the meantime, they could "go at their own pace" (P23, P21). Kindergarten, too, was an opportunity for some of this skill development to take place:

I think when they get to kindergarten I think they more need to learn to be sociable and play with others and have fun[...] I want them to enjoy kindergarten and learn to be around other people more and sharing (P21).

Parents listed several skills needed for being around other children. They included sharing, respecting other children and how to "stick [speak] up for herself if she needs to" (P8). They knew that their child needed to "get used to meeting different kids and dealing with how other kids interact with you" (P12). Readiness also meant children relying less on parents as social contacts and as go-betweens for their social interactions. Without such preparation, "It's just too much of a shock to rock up at school on the first day and go, hey, this is what you're going to be doing" (P1). For this parent, the need for the child to develop this capacity overcame the distance they had to travel to attend activities like LiL or the CFC. However, a few parents who used services less frequently considered their child had sufficient opportunities to socialise through regular interaction with same-aged cousins or children of friends.

Parents tended to see emotional readiness in terms of emotion control, like "being able to share, be a little bit responsible" and knowing that "if you are mean to someone, they are going to be mean back" (P11). Being able to articulate emotions was seen as "a good thing. That's about self-awareness and emotional maturity (P18).

\section{Literacy and Numeracy Readiness}

Parents in the study mostly regarded academic skills (Thomas 2013) (e.g., writing words, counting) as skills that are taught in Kindergarten, “just because he can't write his name on the day that he starts kindergarten doesn't mean he won't be able to write a sentence a year later" (P9). For other parents, these skills were something that they explicitly taught their child or were things the child could just do. One mother said that her son "knew his colours", a sign that "he was ready" (P36). Another child met this readiness domain because she "could talk fairly well. She could count to 20 . She knew her A, B, Cs" (P16). Those parents who taught their child argued that it was important for the child to:

learn at least a few numbers or something and maybe some words. Like, probably not to be able to spell them, but how to say words and at least count numbers, not actually write the numbers down. That's what I do with my children. (P17).
Most parents recognised the importance of reading, and reported they were doing this with their children.

\section{Language and Communication Readiness}

Parents linked language and communication skills with socialising, and with being responsive in class. One parent reported that their child's "communication is really good, too. She'll talk to the children when she needs someone to help them or whatever" (P15). Communication meant expressing needs and this required that the child could speak clearly. Parents wanted to address children's speech and communication problems now, rather than: "leave it till when he's nearly due to go to school and still ha[s] a speech problem" (P21). The social aspects of communication were also part of readiness, as one father pointed out: "I think language might be a big one there too actually-you don't want a child to go to school that thinks it's alright to swear!" (P10).

\section{How Parents See Their Own Role in 'Readiness'}

Parents considered it their role to impart many of the requisite 'readiness' skills to their children, though they framed them more generally as life skills. Encouraging was an important part of this work (e.g., "I will always read them to her because we're always trying to encourage her to be proactive in books", (P2)). Parents wanted to provide opportunities that support their child's readiness, exposing their children to new experiences and activities: "I am her parent, her sole carer, so I think that I should be teaching her all these things, so she can be a better kid" (P13). Some of this was linked with ensuring the child's independence through "just practice and reassuring them: you've got to wash your hands, you've got to do this" (P30). Parents understood much of this teaching or readiness preparation as "all mixed into one. You're playing with toys, you're teaching them to tidy them up, [...] Going outside to play ball or play on the swing, doing physical development. So, without even thinking of teaching them you're teaching them" (P21). Parents were teaching by example and acknowledging their role as teacher "parents have to teach their children listening skills" (P16). They were taking on a training role, focusing on "holding a pen and scissors" (P12), "go[ing] through numbers with her and the alphabet" (P12), and "in the bathtub we count fingers and toes and stuff like that" (P16).

Some parents did not always feel they had the skills to impart the needed lessons and sought the advice of teachers:

... I think I was doing something wrong and then I got advice from teacher or someone here $[\mathrm{CFC}]$... Teachers can teach our children a lot more than what we 
can I think, in certain areas, if you know what I mean. (P16)

\section{Parents Also Being Prepared for School}

It was clear that some pre-school services were also readying parents for their child's schooling. Teachers and other service staff recognised that parents played a critical role in supporting their child's transition to school and were preparing parents for the behaviour expected-of them and of their child-at school. For instance, before reading an end-of-session story, a LiL teacher "addressed the parentsspeaking to them about modelling listening behaviour and paying attention to the story" (fieldnotes). When asked about this, the teacher said that parents "are role models for their children".

The need for 'good manners' was also promoted. At one $\mathrm{LiL}$, this was evident in conversations teachers had with parents and was a feature of "art displays that have a focus on manners, respect, and behaviour. How to speak to other people [and] how to behave in the classroom" (fieldnotes). The researcher noted the link between these displays and "comments from [teacher] today about the large amount of work she needs to put into teaching children and parents what sorts of behaviour are acceptable at school" (fieldnotes). At a CFC, promoting manners occurred via songs and stories. Parents were also encouraged not to speak when the teacher was speaking or use mobile phones in the classroom. Some CFCs displayed posters encouraging parents to put their phones away, linking interaction between parent and child as important for a child's brain development. One teacher commented that they experienced challenges "engaging families who do not always share [their] values and perspectives on their child's development" (fieldnotes).

\section{Services Assisting Parents and Child Prepare for School}

Parents identified the services delivered by the Department of Education (LiL and CFCs) as supporting them to prepare their children for school. Parents valued the CHaPS service, but it was not directly linked to school readiness by parents. LiL and CFCs were considered important in supporting their child's social readiness and preparation for the school environment, particularly for the development of social skills - "a good thing about coming to a place like this [CFC], you get used to meeting different kids and dealing with how other kids interact with you" (P12). These services were identified as important for encouraging children to listen, a skill parents felt was important for learning and managing the transition to school; "the listening and following instructions and things like that which is what LIL is good for" (P20). LiL also introduced children and parents to the school environment, teaching and support staff, and potential classmates. This scaffolded the transition to school. Starting school would be "easier on [them] because [they] sort of seen the teachers around the yard, [they've] been around the school, [they've] been in the kinder yard" (P21).

\section{Discussion}

This study has reported on how parents experience and prepare for their children's transition to school, specifically through their understanding of the concept of 'readiness'. United Nations Children's Fund (UNICEF) (2012) describes school readiness as including three dimensions: that children are supported in their transition into new learning environments, that families learn "to work with a sociocultural system (i.e., education)", and that schools are "making provisions for admitting new children into the system, representing individual and societal diversity" (United Nations Children's Fund (UNICEF) 2012). In Australia, how wellprepared children are is the focus of the AEDC-a measure aimed at assessing children's development before fulltime schooling, in order to shape policy. In 2018, 21.5\% of children in Tasmania, where this study was conducted, have been found to be vulnerable on one or more of the AEDC domains and $10.7 \%$ were vulnerable on two or more domains which reflects the national average of $21.7 \%$ and $11.0 \%$ respectively (Department of Education and Training 2018). The Tasmanian state government has instigated free, universal access to ECS, including LiL, and CFCs, to support families to prepare children for school.

Attending ECS has been shown to bestow long-term educational and socioeconomic benefits (Ramey and Ramey 2004; High 2008; Rosier and McDonald 2011; Arteaga et al. 2014; Shah et al. 2017) with greater use enhancing educational attainment and socioeconomic wellbeing (McLeod et al. 2018). All families in the present study used one or more ECS, albeit with varying regularity. Most parents consider that school readiness is important and saw preparing their child as a role they shared with ECS. Although they spoke in terms of life skills rather than the domains of the AEDC, their views largely matched the expectation implicit in the AEDC that children will benefit from starting formal schooling ready to acquire skills in reading, writing or basic mathematics, and with particular motor and social skills. Parents and early childhood educators conceptualised readiness similarly with respect to supporting the development of their child's physical independence and social skills that would allow them to get along with peers as well as their child's capacity to communicate their needs (Department of Education and Training 2020). In contrast to early childhood educators, parents focused on emotional development with respect to child/parent separation and associated anxiety 
and were less likely to recognise the role they played in the development of school-based language and cognitive skills such as counting, numbers, and shapes (Department of Education and Training 2020). Parents were guided by a desire for their child to be able to negotiate and ultimately thrive —physically, cognitively, socially, and emotionally_in this new setting.

In the physical domain parents were concerned, most particularly, that their child could use the toilet and wash their hands alone as has been previously reported (Millei and Cliff 2014; Whittingham et al. 2018). This was a signal of independence. They also saw the need for motor skills like the ability to hold a pen, run and skip, or ride a bike; for some parents, this extended to the capacity to conform to the body-practices of the classroom such as sitting cross-legged (Comber 2000; Burke and Duncan 2016).

There were other school norms, too, that parents linked with their child's chances of succeeding in this new environment. Perhaps the most prominent related to social-emotional independence. The child needed to be confident to be away from the parent and have the skills to initiate and negotiate new relationships. Other forms of social readiness include emotional maturity factors such as not fighting and being obedient, which parents grouped with following instructions and being sociable. This echoes the proposal (Mashburn and Pianta 2006) that children's interactions and relationships with peers, parents, and teachers are the source of many of the readiness skills that educators value. Other studies have also argued for the importance of these 'fitting in' skills (Piotrkowski et al. 2000; McBryde et al. 2004; McAllister et al. 2005). Duncan et al. (2007) reported that the strongest predictors of later achievement are school-entry mathematical, reading, and attention skills, with social skills a poor indicator irrespective of socioeconomic background. Nonetheless, parents in the present study believed their child should have social-emotional and motor skills, as well as foundational (pre-academic) literacy and numeracy skills at the start of formal schooling and understood their own central role in their child's readiness for school.

This role, in turn, meant that parents needed to be prepared for the task as outlined by UNICEF (United Nations Children's Fund (UNICEF) 2012) and reflects the relational view of learning embedded in the Australian Early Learning Framework (Australian Department of Education and Training 2009). The programs that families attended implicitly taught parents "to work with a sociocultural system" (United Nations Children's Fund (UNICEF) 2012). This was evident in reminders-directed both at parents and at the child-about what sorts of behaviours are acceptable at school: good manners, respect, not talking when the teacher talks, and not using mobile phones.

The finding here that parents are being prepared by the LiL and CFC services for the social norms of school complements earlier work (McAllister et al. 2005) focusing on parents' emotional readiness to support the child's transition to school. In that study, this role was particularly noted by parents who experienced school as a "foreign and sometimes dangerous place". Some parents in this study revealed that school could provoke anxiety, particularly with respect to separation from their child, but the source of this anxiety was not elucidated.

\section{Strengths and Limitations}

While this study has examined the perspectives of parents on their child's school readiness, and we have some information about how the teachers in the study understand readiness, we did not ask children about preparing for school. The perspectives of parents' whose children did not attend any form of ECS were also not captured as all parents had some contact with ECSs, albeit limited in some circumstances. A second limitation is that the project sites were all characterised by socio-economic disadvantage; we cannot generalise these findings to all users of ECS, nor assume that LiL and CFCs in other settings would be understood in the way parents reported here. This study benefited from an extended period in the field, which allowed for repeat interviews with parents. School readiness was discussed in both interviews, and findings from first interviews were followed up in detail in the second. This also enabled member checking, so that parents could review, expand upon, or correct their earlier input. The study design and time also supported the extensive observation of early childhood education settings, and casual conversations with parents who were not formally part of the study.

\section{Conclusion}

The findings presented in this paper support the view that parents who attend ECS understand ECS as beneficial to their children's transition to school. Readiness, a concept that is broadly accepted by educators and policy-makers, was understood by families, though their interpretation differed. Where the literature and AEDC define readiness using a series of markers (e.g., physical health and wellbeing, social and emotional competence, language and cognition, communication, general knowledge, attitudes and behaviour), for parents, readiness was about their child's capacity to operate effectively and independently in the hitherto unfamiliar physical and social world of school. Despite this difference in framing, parents could see the benefits for their children of services that build readiness, and valued the ECS offered. Despite parents in this study conceptualising 'school readiness' somewhat differently 
to educators there was broad agreement with and efforts made to attend ECS, signalling policy success.

Acknowledgements We would like to thank all study participants for their time and willingness to participate in the study. We acknowledge the partnership of the Tasmanian Department of Education, Department of Health and Department of Premier and Cabinet to conduct this work. We acknowledge the Tasmanian Department of Education and Department of Health who provided data for this project. This work does not necessarily reflect the view of the government departments involved in the research.

Author contributions $\mathrm{KJ}$ contributed to study design, data collection, data analysis and interpretation, and writing of this manuscript. SB contributed to data collection, analysis and writing. EH contributed to study design, data interpretation, and writing. RJ contributed to data collection, analysis, and writing. SZ contributed to study design, data interpretation, and writing. JS contributed to study design, data interpretation, and writing. CT contributed to study design, data interpretation, and writing. All authors read and approved the final manuscript.

Funding This work was supported by the Australian National Health and Medical Research Council Partnership Project Grant (APP1115891). KJ, RJ, and JS were supported by a Partnership Project grant from the National Health and Medical Research Council Australia (1115891) and the Tasmanian Department of Education, Department of Health and Human Services and Department of Premier and Cabinet. CLT, SRZ, and JS were supported by the Australian Research Council Centre of Excellence for Children and Families over the Life Course (CE140100027). The funding bodies listed had no role in the design of the study, collection, analysis, and interpretation of data or writing of the manuscript.

Data Availability The datasets generated and/or analysed during the current study are not publicly available due to the potential to compromise participant privacy. Participants did not consent to have their full transcripts made publicly available. Selected excerpts are available from the corresponding author on reasonable request.

\section{Compliance with Ethical Standards}

Conflicts of interest The authors declare that they have no conflict of interest.

Consent to Participate All participants provided written informed consent for interviews and participant observation.

Ethics Approval Ethical approval was received from the Tasmanian Human Research Ethics Committee (H0016195). The procedures used in this study adhere to the tenets of the Declaration of Helsinki.

OpenAccess Thisarticleslicensed under a Creative Commons Attribution 4.0 International License, which permits use, sharing, adaptation, distribution and reproduction in any medium or format, as long as you give appropriate credit to the original author(s) and the source, provide a link to the Creative Commons licence, and indicate if changes were made. The images or other third party material in this article are included in the article's Creative Commons licence, unless indicated otherwise in a credit line to the material. If material is not included in the article's Creative Commons licence and your intended use is not permitted by statutory regulation or exceeds the permitted use, you will need to obtain permission directly from the copyright holder. To view a copy of this licence, visit http://creativecommons.org/licenses/by/4.0/.

\section{References}

Arteaga, I., Humpage, S., Reynolds, A. J., \& Temple, J. A. (2014). One year of preschool or two: Is it important for adult outcomes? Economics of Education Review, 40, 221-237.

Australian Bureau of Statistics. (2016). Census of population and housing: SOCIO-Economic Indexes For Areas (SEIFA), Australia, 2016. Australian Bureau of Ststistics: Canberra.

Australian Curriculum Assessment and Reporting Authority. (2016). National assessment program-literacy and numeracy: Achievement in reading, writing, language conventions and numeracy. National Report for 2016. Canberra: ACARA.

Australian Department of Education and Training. (2009). Belonging, being and becoming - the early years learning framework. Canberra: Commonwealth of Australia.

Bazeley, P., \& Jackson, K. (2013). Qualitative data analysis with Nvivo. London: Sage.

Brinkman, S. A., Gregory, T. A., Goldfeld, S., Lynch, J. W., \& Hardy, M. (2014). Data resource profile: The Australian Early Development Index (AEDI). International Journal of Epidemiology, 43(4), 1089-1096.

Britto, P. R., Lye, S. J., Proulx, K., Yousafzai, A. K., Matthews, S. G., Vaivada, T., et al. (2017). Nurturing care: promoting early childhood development. The Lancet, 389(10064), 91-102.

Bronfenbrenner, U., \& Morris, P. (2006). The bioecological model of human Development. In R. Lerner \& W. Damon (Eds.), Handbook of child psychology: Theoretical models of human development (pp. 793-828). Hobocken: Wiley.

Burke, R. S., \& Duncan, J. (2016). Culturally contested corporeality: Regulation of the body in New Zealand and Japanese early childhood education. Global Studies of Childhood, 6(1), 6-16.

Clerke, T., \& Hopwood, N. (2014). Doing ethnography in teams: A case study of asymmetries in collaborative research. Heidelberg: Springer.

Comber, B. (2000). What Really Counts in Early Literacy Lessons. Language Arts, 78(1), 39-49.

Council of Australian Governments. (2009). Investing in the early years - a national early childhood development strategy. Retrived February 14, 2019, from https://www.startingblocks.gov.au/media /1104/national_ecd_strategy.pdf.

Cresswell, J. (2007). Qualitative inquiry and research design. Thousand Oaks: SAGE.

Department of Education and Training. (2015). Australian Early Development Census National Report 2015: A snapshot of early child development in Australia: Department of Education and Training. https://www.aedc.gov.au/resources/detail/2015-aedc-natio nal-report.

Department of Education and Training. (2018). Australian Early Development Census National Report 2018: A snapshot of early childhood development in Australia. Retrived June 28, 2019, from https ://www.aedc.gov.au/resources/detail/2018-aedc-national-report.

Department of Education and Training. (2020). Australian Early Development Census, Resources for parents. Retrived January 13, 2020, from https://www.aedc.gov.au/parents/resources-for-parents.

Domitrovich, C., Moore, J., Thompson, R., \& CASEL (2012). Preschool to elementary school social and emotional learning assessment group. In R. Pianta (Ed.), Interventions that promote socialemotional learning in young children. New York: Guilford Press.

Duncan, G. J., Dowsett, C. J., Claessens, A., Magnuson, K., Huston, A. C., Klebanov, P., et al. (2007). School readiness and later achievement. Developmental Psychology, 43(6), 1428-1446.

Grbich, C. (1998). Qualitative research in health. London: SAGE.

Guhn, M., Gadermann, A. M., Almas, A., Schonert-Reichl, K. A., \& Hertzman, C. (2016). Associations of teacher-rated social, emotional, and cognitive development in kindergarten to self-reported 
wellbeing, peer relations, and academic test scores in middle childhood. Early Childhood Research Quarterly, 35, 76-84.

Hansen, E. (2006). Successful qualitative health research: A practical introduction. Crows Nest: Allen \& Unwin.

High, P. C. (2008). School readiness. Pediatrics, 121(4), e1008-e1015.

Lofland, J., Snow, D., Anderson, L., \& Lofland, L. (2006). Analyzing social settings. Belmont: Wadsworth.

Mashburn, A. J., \& Pianta, R. C. (2006). Social relationships and school readiness. Early Education and Development, 17(1), 151-176.

McAllister, C. L., Wilson, P. C., Green, B. L., \& Baldwin, J. L. (2005). "Come and take a walk": Listening to early head start parents on school-readiness as a matter of child, family, and community health. American Journal of Public Health, 95(4), 617-625.

McBryde, C., Ziviani, J., \& Cuskelly, M. (2004). School readiness and factors that influence decision making. Occupational Therapy International, 11(4), 193-208.

McLeod, G. F. H., Horwood, L. J., Boden, J. M., \& Fergusson, D. M. (2018). Early childhood education and later educational attainment and socioeconomic wellbeing outcomes to age 30. New Zealand Journal of Educational Studies, 53, 257-273.

Millei, Z., \& Cliff, K. (2014). The preschool bathroom: making 'problem bodies' and the limit of the disciplinary regime over children. British Journal of Sociology of Education, 35(2), 244-262.

Miller, M. M., \& Kehl, L. M. (2019). Comparing parents' and teachers' rank-ordered importance of early school readiness characteristics. Early Childhood Education Journal, 47(4), 445-453.

Organization for Economic Co-operation and Development. (2016). Education at a Glance 2016: OECD Indicators. Paris: OECD.

Piotrkowski, C. S., Botsko, M., \& Matthews, E. (2000). Parents' and teachers' beliefs about children's school readiness in a high-need community. Early Childhood Research Quarterly, 15(4), 537-558.

Ramey, C. T., \& Ramey, S. L. (2004). Early learning and school readiness: Can early intervention make a difference? Merrill-Palmer Quarterly, 50(4), 471-491.
Reeves, S., Kuper, A., \& Hodges, B. D. (2008). Qualitative research methodologies: ethnography. BMJ, 337, a1020.

Rosier, K., \& McDonald, M. (2011). Promoting positive education and care transitions for children. Canberra, ACT: Australian Institute of Family Studies.

Shah, H. K., Domitrovich, C. E., Morgan, N. R., Moore, J. E., Cooper, B. R., Jacobson, L., et al. (2017). One or two years of participation: Is dosage of an enhanced publicly funded preschool program associated with the academic and executive function skills of low-income children in early elementary school? Early Childhood Research Quarterly, 40, 123-137.

Tayler, C., Cloney, D., \& Niklas, F. (2015). A bird in the hand: Understanding the trajectories of development of young children and the need for action to improve outcomes [online]. Australasian Journal of Early Childhood, 40(3), 51-60.

Taylor, C., Jose, K., van de Lageweg, W. I., \& Christensen, D. (2017). Tasmania's child and family centres: A place-based early childhood services model for families and children from pregnancy to age five. Early Child Development and Care, 187(10), 1496-1510.

Taylor, C. L., Zubrick, S. R., \& Christensen, D. (2019). Multiple risk exposures for reading achievement in childhood and adolescence. Journal of Epidemiology and Community Health, 73(5), 427-434.

United Nations Children's Fund (UNICEF). (2012). School readiness: A conceptual framework. New York: United Nations Children's Fund.

Whittingham, C. E., Hoffman, E. B., \& Rumenapp, J. C. (2018). "It ain't 'nah' it's 'no"': Preparing preschoolers for the language of school. Journal of Early Childhood Literacy, 18(4), 465-489.

Publisher's Note Springer Nature remains neutral with regard to jurisdictional claims in published maps and institutional affiliations. 